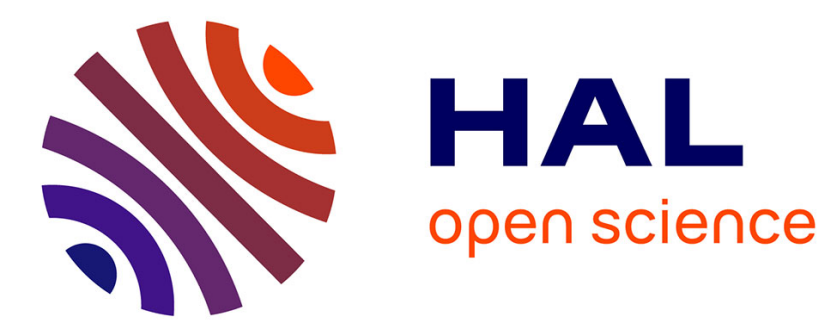

\title{
Self-Catalyzed Growth of Highly Vertical GaAs Core-Shell Nanowires on Chemically-Treated $\mathrm{Si}(111)$ Surfaces
}

Siew Li, Yann Genuist, Henri Mariette, Nikos T Pelekanos

\section{- To cite this version:}

Siew Li, Yann Genuist, Henri Mariette, Nikos T Pelekanos. Self-Catalyzed Growth of Highly Vertical GaAs Core-Shell Nanowires on Chemically-Treated Si(111) Surfaces. 2016 Compound Semiconductor Week, Jun 2016, Toyama, Japan. hal-02064662

\section{HAL Id: hal-02064662 https://hal.science/hal-02064662}

Submitted on 12 Mar 2019

HAL is a multi-disciplinary open access archive for the deposit and dissemination of scientific research documents, whether they are published or not. The documents may come from teaching and research institutions in France or abroad, or from public or private research centers.
L'archive ouverte pluridisciplinaire HAL, est destinée au dépôt et à la diffusion de documents scientifiques de niveau recherche, publiés ou non, émanant des établissements d'enseignement et de recherche français ou étrangers, des laboratoires publics ou privés. 


\title{
Self-Catalyzed Growth of Highly Vertical GaAs Core-Shell Nanowires on Chemically-Treated Si(111) Surfaces
}

\author{
Siew Li Tan ${ }^{1,2}$, Yann Genuist ${ }^{1,3}$, Henri Mariette ${ }^{2,3}$, and Nikos T. Pelekanos ${ }^{1,2,4}$ \\ ${ }^{1}$ CEA, INAC, 17 rue des Martyrs, 38054 Grenoble cedex 9, France \\ ${ }^{2}$ Univ. Grenoble Alpes, F-38000 Grenoble, France \\ ${ }^{3}$ CNRS, Inst NEEL, F-38000 Grenoble, France \\ ${ }^{4}$ Department of Materials Science and Technology, University of Crete, P.O. Box 2208, 70013 Heraklion, \\ Greece. \\ E-mail: pelekano@materials.uoc.gr
}

\begin{abstract}
The reproducibility of self-catalyzed molecular beam epitaxy growth of GaAs nanowires (NWs) on oxidecovered $\mathrm{Si}(111)$ substrates depends on the consistent quality of the oxide layer. We have developed an effective chemical treatment method to create oxide surfaces that are conductive to the nucleation of vertical GaAs NWs on $\mathrm{Si}(111)$. Here we demonstrate a high yield exceeding $90 \%$ of vertical GaAs NWs with density in the order of $10^{9} \mathrm{~cm}^{-2}$. Using a combination of chemical oxide treatment and in situ growth conditions, we investigate how to achieve a good control of the morphology and density of GaAs and GaAs/III-As core-shell NWs grown on $\mathrm{Si}$.
\end{abstract}

\section{Keywords-GaAs nanowires; molecular beam epitaxy; Ga-assisted growth; chemical treatment}

III-V compound semiconductor nanowires (NWs) are a promising building block for nanoscale optoelectronic devices. Their less critical lattice-matching requirements enable flexible integration of a wide range of III-V materials in the form of NWs on cost-effective Si substrates. The growth of III-V NWs can be performed using a variety of deposition techniques via growth mechanisms similar to the vapor-liquid-solid (VLS) process, which requires a metal nanodroplet catalyst [1]. This work focuses on the self-catalyzed (also known as the Ga-assisted) growth of GaAs NWs using molecular beam epitaxy (MBE) technique, in which Ga catalytic droplets are deposited in situ to avoid defects and contamination caused by the use of extrinsic catalyst material. Recent studies have shown that a non-wetting oxide-covered surface is necessary for the formation of Ga droplets with the right contact angle to enable successful nucleation of vertical GaAs NWs on $\mathrm{Si}(111)$ [1,2]. There have been reports on $\mathrm{Ga}$-assisted growth of $\mathrm{NWs}$ on $\mathrm{Si}(111)$ substrates covered by different types of native or fabricated oxide $\left(\mathrm{SiO}_{2}\right.$ or $\left.\mathrm{SiO}_{\mathrm{x}}\right)$ layers [2-4]. However, it remains challenging to achieve a high yield of vertical NWs and the reproducibility of the NW morphology and density tends to vary from batch to batch of Si wafers.

In this work, we investigate the effects of chemical treatment and oxidation of $\mathrm{Si}(111)$ substrate on the yield and reproducibility of vertical GaAs NWs. The growth of NWs is carried out on 2-inch As-doped $\mathrm{Si}(111)$ wafers manufactured by Siltronix, using a solid-source Riber 32P MBE system. Prior to loading the wafer into the MBE chamber, the native oxide on the $\mathrm{Si}(111)$ substrate is treated with a chemical solution to increase the density of nanosized pinholes for NW nucleation. To highlight the issue of reproducibility, we compare the morphology of GaAs NWs grown on two different batches of $\mathrm{Si}(111)$ wafers by the same manufacturer, under similar growth conditions. Fig. 1 compares the surface morphology by atomic force microscopy (AFM) of the untreated native oxide-covered $\mathrm{Si}(111)$ substrates from the two wafer batches, namely A and $\mathrm{B}$. The rms roughness of batch A substrates is about $45 \%$ higher than that of batch B substrates. As shown in Figs. 2(a)/(d) and (b)/(e), the resultant GaAs NWs are similar in height $(\sim 1.7 \mu \mathrm{m})$ but differ significantly in density. In order to eliminate dependency on the polishing conditions of the wafers (which affect the quality of the native oxide layer), we have developed an effective wet chemical method to create a pinhole-containing chemical oxide layer on the Si surface following native oxide removal. Using this method, we have achieved a high yield of vertical GaAs NWs exceeding $90 \%$ for NW density in the order of $10^{9} \mathrm{~cm}^{-2}$, as shown in Figs. (c)/(f). Finally, we investigate how the morphology and density of not only GaAs but also GaAs/III-As core-shell NWs can be controlled via the combination of chemical oxide treatment and in situ growth conditions.

\section{ACKNOWLEDGMENTS}

This work is partly funded by the Chair of Excellence program of the "Laboratoire d'excellence LANEF" in Grenoble, France (ANR-10LABX-51-01).

\section{REFERENCES}

[1] A. F. Morral, "Gold-Free GaAs Nanowire Synthesis and Optical Properties," IEEE J. Sel. Top. Quantum Electron., vol. 17, no. 4, pp. 819-828, 2011.

[2] F. Matteini, et al., "Wetting of $\mathrm{Ga}$ on $\mathrm{SiO}_{\mathrm{x}}$ and its impact on GaAs nanowire growth on silicon," Crystal Growth \& Design, vol. 15, no. 7, pp. 3105-3109, 2015.

[3] L. T. T. Giang, et al., "Intrinsic limits governing MBE growth of Ga-assisted GaAs nanowires on Si(111)," J. Cryst. Growth, vol. 364, pp. 118-122, 2013

[4] F. Matteini, et al., "Ga-assisted growth of GaAs nanowires on silicon, comparison of surface SiO ${ }_{x}$ of different nature," J. Cryst. Growth, vol. 404, pp. 246-255, 2014. 

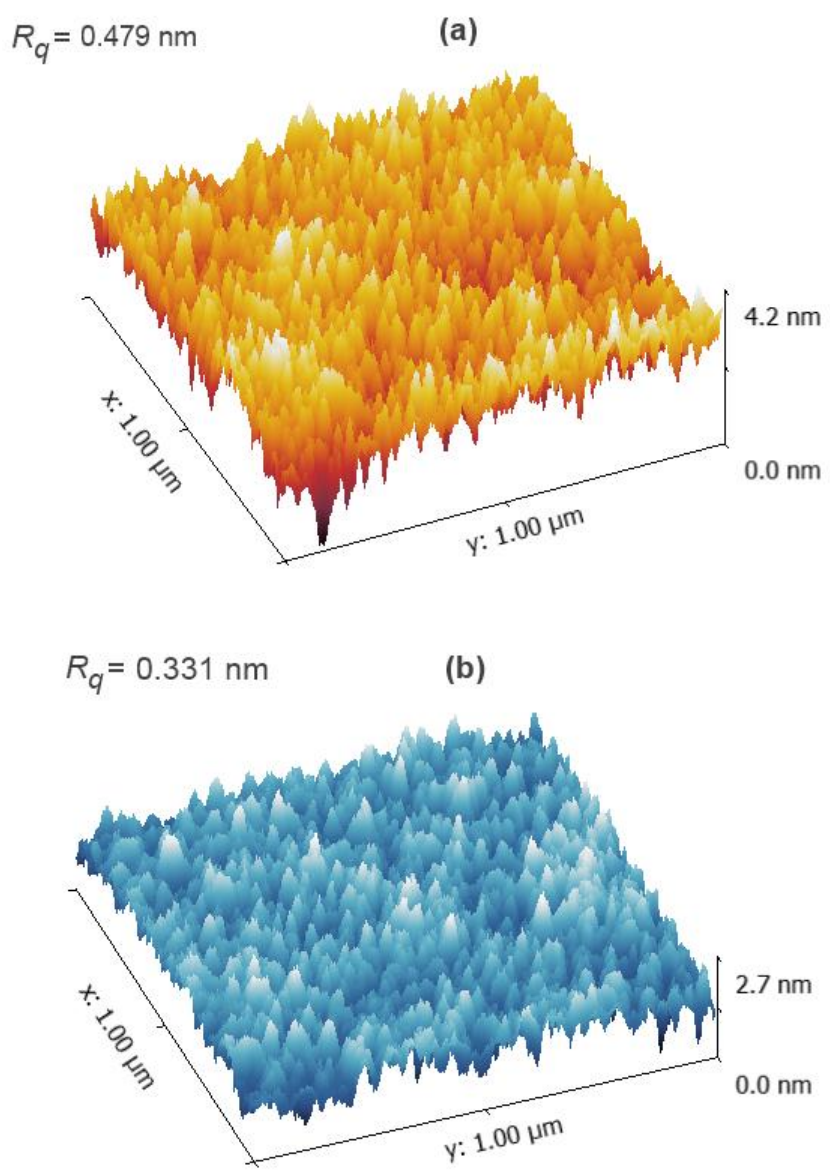

Fig. 1. Three-dimensional AFM morphology of $\mathrm{Si}(111)$ substrate from (a) wafer batch A and (b) wafer batch B with root-mean-square (rms) roughness of $0.479 \mathrm{~nm}$ and $0.331 \mathrm{~nm}$, respectively.

(a)

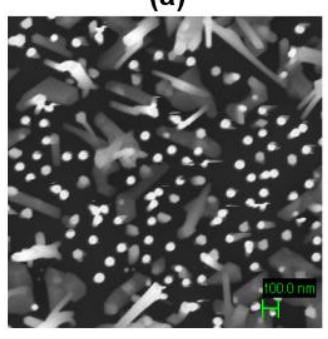

(d)

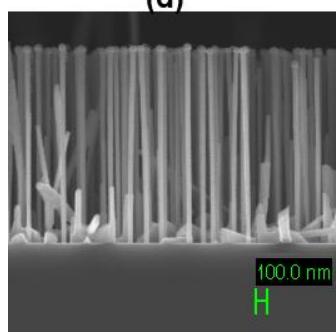

(b)

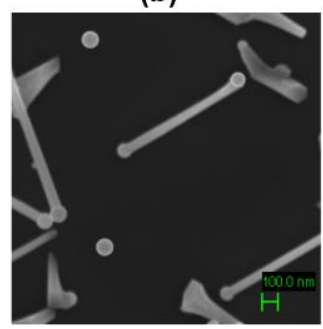

(e)

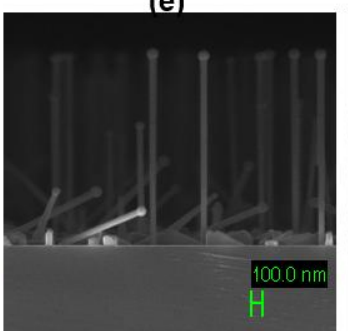

(c)

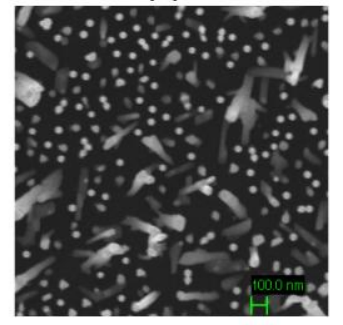

(f)

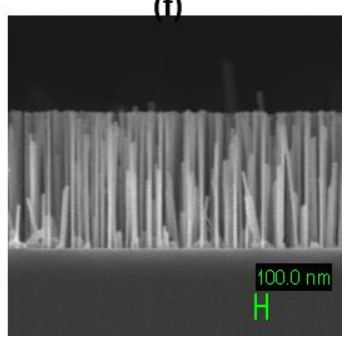

Fig. 2. Plane-view SEM images of GaAs nanowires grown under similar conditions on $\mathrm{Si}(111)$ substrate from (a) batch A with chemically-treated native oxide, (b) batch B with chemically-treated native oxide, and (c) batch B with chemical oxide layer. The corresponding cross-sectional SEM images are shown in

(d) for sample in (a), (e) for sample in (b), and (f) for sample in (c). All images are taken at the same magnification. The scale bars represent $100 \mathrm{~nm}$. 